\title{
O processo de geração de sentidos e sua importância para a
}

\section{transcrição de uma obra musical}

\author{
Victor Vale, Flavio Barbeitas
}

Universidade Federal de Ouro Preto, Universidade Federal de Minas Gerais | Brasil

\begin{abstract}
Resumo: A prática de transcrição tem sido um elemento presente no desenvolvimento histórico da música ocidental de tradição escrita. Motivada pelo desejo de apropriação e ampliação de repertório, tal prática se estabeleceu num quadro de submissão ao universo idiomático-estético de chegada, de forma tal que o texto transcrito viesse a se adequar da melhor forma possível ao funcionamento mecânico e à cultura do instrumento de destino. $\mathrm{O}$ artigo sugere que, ao privilegiar a operacionalidade da obra no instrumento para o qual transcreve, o transcritor distorce o tecido expressivo-significante em potência no texto de origem, o qual é fruto da interseção estabelecida entre o universo idiomático e o discurso musical de partida. A aproximação com as teorias da tradução pós-Goethe, calcadas na filosofia da experiência, possibilita um novo olhar para a prática transcritiva, conferindo uma relação mais ética e poética com a obra a ser transcrita.
\end{abstract}

Palavras-chave: Transcrição musical, Tradução literária, Idiomatismo instrumental, Significância, Violão.

\begin{abstract}
The practice of transcription has been a constituent element in the historical development of Western music of written tradition. Motivated by the desire for appropriation and expansion of repertoire, such practice was established in a framework of submission to the idiomatic aesthetic universe of arrival, so that the transcribed text could best fit the mechanical functioning and culture of the instrument of destination. The article suggests that, by privileging the operability of the work on the instrument to which he transcribes, the transcriptor distorts the expressivesignificant texture in potential in the source text, which is the result of the intersection established between the idiomatic universe and the musical discourse of departure. The approach to post-Goethean theories of translation, based on the philosophy of experience, enables a new look at transcriptional practice, giving a more ethical and poetic relationship with the work to be transcribed.
\end{abstract}

Keywords: Musical transcription, Literary translation, Idiomatic writing, Significance, Guitar. 


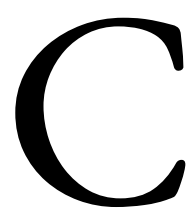

ientes de que a atividade de transcrição musical sempre desempenhou um papel significativo na expansão do repertório do violão, a nossa proposta no presente artigo

visa a enquadrar essa prática numa perspectiva mais teórica e informada, principalmente levando em conta questóes estéticas que, embora relevantes, são, em geral e por motivos que ficarão claros ao longo do artigo, desprezadas pelos transcritores.

Fruto de uma de pesquisa de doutorado concluída em 2018 no Programa de Pós-graduação em Música da UFMG (VALE, 2018), o artigo persegue, apoiado por referenciais teóricos dos estudos de tradução, uma reflexão em torno do complexo processo de geração de sentidos numa obra musical a sua significância - e de como ele pode orientar a elaboração de transcrições. A título de ilustração, apresentamos, ao final, as questôes em jogo na transcrição para violão de um trecho da Bourrée da Partita BWV 1002, de J. S. Bach.

\section{A prática transcritiva: um breve panorama e uma proposta analítica.}

É possível afirmar que a prática da transcrição musical está de tal forma imbricada com os caminhos da música ocidental de tradição escrita que se tornou, por assim dizer, testemunha direta de seus desdobramentos históricos, tanto no nível técnico e teórico quanto em termos socioculturais. De resto, a importância das práticas transcritivas pode ser atestada não apenas por suas explícitas e expressivas repercussóes no desenvolvimento do repertório de vários instrumentos - com especial destaque no caso do violão -, mas também pelo grande número de pesquisas e estudos que, mais recentemente, as elegeram como objeto de investigação.

Especificamente no âmbito dessas reflexões ${ }^{1}$, percebe-se que o tema da transcrição impulsiona considerável debate, que abarca a pertinência e qualidade das adaptaçôes repertoriais, as diversas categorias transcritivas relativas às tradições escrita e oral, e a própria experiência analítica - conatural à transcrição - operante na desconstrução dos elementos e na consequente conscientização das estruturas de uma obra musical. Em que pese a recorrência do tema da transcrição, nossa abordagem segue caminhos diversos em relação ao que comumente se observa. Não tanto porque se propõe aqui

\footnotetext{
${ }^{1}$ Alguns exemplos de trabalhos que apresentam a prática transcritiva como escopo e/ou ferramenta de análise: COSTA (2012), PEREIRA (2011), RIBEIRO (2014), RODRIGUES (2011), SIMÃO (2013).
} 
uma aproximação da transcrição com as teorias da linguagem e da tradução - algo certamente não inédito $^{2}-$, mas porque a reflexão que faremos sobre essa analogia visa explorar um terreno ainda bem pouco visitado. Em nossa abordagem, elementos, teorias e conceitos problematizados pelos estudos sobre linguagem e tradução ganham espaço e se tornam o fio condutor da análise sobre a dinâmica, a experiência e o funcionamento do processo de transcrição musical.

Para que fique clara a especificidade da abordagem proposta, é útil iniciar por uma caracterização sucinta. Pode-se dizer que boa parte dos estudos dedicados à transcrição parte da função eminentemente prática, historicamente estabelecida, que a constituiu como recurso para suprir lacunas do repertório. E, deve-se dizer, tais estudos não costumam extrapolar esse âmbito, decorrendo de tal postura a extração de um princípio teórico que cumpre logo ressaltar: a transcrição tende a ser concebida como construto prisioneiro das leis e estruturas que regem o universo idiomático de destino, isto é, da rede de conjuntos e procedimentos técnico-mecânicos que formam o idiomatismo do instrumento para o qual a obra é transcrita. Toda a tradição transcricional baseada nesse princípio tem alimentado a tentativa de silenciar e pasteurizar aqueles comportamentos mecânicos, em potência no texto musical de origem, que se revelassem estranhos ao melhor rendimento possível no instrumento de destino e no novo espaço idiomático. Curiosamente, tal concepção no âmbito da transcrição musical é plenamente convergente com correntes tradicionais da tradução poética que, contudo, não obstante uma elaboração teórica bem maior se comparada com a transcrição musical, tornaram-se, já há algum tempo, objeto de avançada desconstrução por parte de estudiosos notáveis de que se falará a seguir. Flagrar os pontos de convergência teórica e estética entre transcrição e tradução irá permitir não apenas uma boa caracterização dos princípios subjacentes às práticas transcritivas mais correntes, mas também descortinar outras possibilidades de se conceber a transcrição musical, talvez mais compassadas com os questionamentos contemporâneos das práticas tradutórias.

\footnotetext{
${ }^{2} \mathrm{~A}$ aproximação entre música e linguagem, configurada por meio da análise de suas práticas transcritivas e tradutórias, é um tema que, já há algumas décadas, vem sendo trabalhado no interior dos estudos musicológicos. Podemos encontrar essa temática, por exemplo, em BARBEITAS (2000), UNES (1998), BOTA (2017), entre outros.
} 


\section{A desconstrução do platonismo no interior da tradição tradutória.}

$\mathrm{Na}$ tradição tradutória, predominam procedimentos direcionados e comprometidos exclusivamente com o universo linguístico do leitor, com os valores, padróes e idiossincrasias de sua cultura. Nesse cenário, a atividade tradutória acaba vinculada ao etnocentrismo, fenômeno profundamente problematizado e debatido, em âmbito linguístico, por filósofos como Antoine Berman (2007), Walter Benjamin (1979), Paul Ricoeur (2012) e Peeter Torop (2000). Para Berman, uma tradução etnocêntrica é aquela que "traz tudo à sua própria cultura, às suas normas e valores, e considera o que se encontra fora dela - o Estrangeiro - como negativo ou, no máximo, bom para ser anexado, adaptado para aumentar a riqueza desta cultura" (BERMAN, 2007, p. 28). Nesse paradigma tradutório - e transcritivo, vale sempre insistir - percebe-se a latência de um núcleo inequivocamente platônico que deve ser evidenciado: a polaridade de corpo e alma, sensível e inteligível, logos e pathos, recorrentemente mimetizada no ethos da cultura ocidental. $\mathrm{Na}$ teoria da tradução, a polaridade se mantém desde as origens e encontra atualização na célebre dicotomia de forma e sentido em que se costuma enquadrar um texto. O privilégio é dado ao sentido em detrimento do funcionamento, da mecanicidade e da organicidade da língua, apesar do fato de esses atributos estarem presentes em qualquer texto objeto de tradução e nele atuarem. Formou-se, regido por esse contrato original, um imenso conjunto de traduçốes cujo objetivo principal foi a completa e excludente subserviência aos núcleos linguísticos, morais e culturais de seus leitores, abrindo mão de possíveis estranhamentos léxicos, sintáticos e semânticos que pudessem ameaçar, no texto de destino, a hegemonia absoluta e transparente do sentido.

Contudo, justamente no espaço que essa concepção etnocêntrica e platônica do traduzir intentou obscurecer e velar, outra corrente tradutória se desenvolveu, mostrando-se "ética, poética e pensante” (BERMAN, 2007, p. 34). Nesse contexto, a tradução muito se assemelha à prática filosófica, uma vez que também é realizada pela via de mão dupla experiência-reflexão. Segundo Heidegger,

Toda tradução é em si mesma uma interpretação. Ela carrega no seu ser, sem dar-lhes voz, todos os fundamentos, as aberturas e os níveis da interpretação que estavam na sua origem. E a interpretação, por sua vez, é somente o cumprimento da tradução que permanece calada (...). Conforme às suas essências, a interpretação e a tradução são somente uma e única coisa. (HEIDEGGER apud BERMAN. 2007, p. 26) 
Atravessada pelo exercício filosófico e hermenêutico, essa outra forma de se pensar a tradução não objetivaria a pura e transparente primazia do sentido, como era comum à prática tradutória préGoethe $^{3}$. A partir desse momento, o ataque ao platonismo no interior do pensamento sobre a tradução se torna o ponto de convergência de duas premissas problematizadas por todos os teóricos da linguagem citados anteriormente, cada qual com sua própria via de análise. A primeira diz respeito ao componente semântico. Para esses teóricos, não haveria um universo significante e inteligível único, a pairar sobre todas as línguas de modo a permitir a realocação do sentido através da eleição de estruturas “equivalentes” nos mais diversos vernáculos. Pelo contrário, a tradução deveria corresponder a uma experiência de luta travada com a carnalidade e a organicidade da língua de origem, tensão que de algum modo deve ser reconstruída na língua de destino - precisamente o que a matriz platônica e etnocêntrica buscou suprimir e recalcar a fim de preservar da pulverização a clareza e a transparência semânticas.

Esse ponto nos conduz à segunda premissa. A condição transitiva de toda atividade tradutória, como também de todo processo transcricional, nos leva a admitir a existência de duas unidades informativas, uma de raiz geográfica e outra, composicional. Pela unidade geográfica, questionam-se os caminhos do processo transitivo, seus pontos de partida e chegada (de onde e para onde se estabelece $o$ ato tradutório?). Por sua vez, a unidade composicional requer o questionamento da condição material (o que está ou deveria estar em deslocamento na tradução?). Apesar de a questão parecer um tanto óbvia, é justamente sobre esse ponto que se debruça grande parte dos estudos modernos que visa iluminar a prática da tradução e o processo de construção de sentido nas línguas. E no interior dessa grande problematização, parece ser consenso que a construção semântica é resultante da (tensa) interseção entre a mecanicidade das línguas e o universo inteligível das ideias. Visto que o funcionamento das línguas, oriundo da dinâmica de seus corpos e mecânicas, revela-se absolutamente singular em todo e qualquer vernáculo, a construção do sentido também será única e pontual em cada um desses territórios linguísticos, resultado do recorte que cada universo vernacular realiza no plano inteligível. A língua de determinado país ou povo não traduz apenas suas coordenadas sociocomunicativas ou o seu primitivo e basal devir verbo, mas também, e de forma latente, sua

\footnotetext{
${ }^{3}$ Tradição tradutória que evidenciava a primazia do sentido em detrimento da palavra. Berman (2007) dizia que tal tradição gerou um epifenômeno tradutório que tinha como objetivo eliminar todo e qualquer estrangeirismo do texto traduzido, como se esse tivesse sido extraído da própria cultura para a qual se traduz.
} 
própria dinâmica relacional com o mundo. Ter tornado irrelevante esse contexto carnal em um ato tradutório - que, pelo contrário, é absolutamente essencial não apenas para a estrutura semântica do texto, mas para a própria circunscrição do autor dentro de um universo singular, com cultura, moral, costumes e visão de mundo também singulares - fez sedimentar ainda mais uma antiga e recorrente visão pejorativa pela qual se acusa a impossibilidade da tradução e a sua perpétua permanência no limbo da interlíngua ${ }^{4}$. Um caso esclarecedor da presença da corporalidade no ato tradutório e que nos serve para o devido contorno da questão de que estamos tratando, ainda antes de deslocar nossa atenção à transcrição musical, é o da autotradução, principalmente se compreendido pelas seguintes palavras de Cyril Aslanov,

A problemática da autotradução, caso-limite da tradução, revela a essência da arte interpretativa. $\mathrm{O}$ tradutor de seu próprio texto não pode mantê-lo no mesmo estado de redação porque ele mesmo já mudou muito desde o momento em que escreveu a primeira versão da obra. (...) Além disso, o autor, embora seja a mesma pessoa, não tem sempre a mesma pessoalidade, independentemente da língua que está falando ou na qual está escrevendo. Uma língua dita certo tom, certo jeito que é irredutível em outra língua, de modo que o tradutor que se reescreve em outro idioma (mais do que se traduz para ele) tem outro estilo, outro gosto e até outra concepção do mundo. (ASLANOV, 2015, p. 12-13).

\section{A problemática em torno do núcleo geográfico inerente ao fenômeno transcricional.}

Ao transportar esse debate para o contexto da transcrição musical, não apenas nos deparamos com problemáticas e dinâmicas semelhantes, como também somos impelidos a dar respostas a outros questionamentos que resultam de novas vias de entrada analítica. Se a discussão sobre a prática tradutória gira, na grande maioria das vezes, em torno de seu núcleo composicional, ao nos confrontarmos com o universo da transcrição verificamos que não apenas seus elementos constituintes são passíveis de análise e debate, mas também a especificidade de sua raiz geográfica nos obriga a pensar sobre suas inúmeras particularidades. Assim, ainda antes de nos debruçarmos sobre as texturas e arranjos decorrentes da raiz composicional da transcrição musical, é fundamental colocarmos em perspectiva algumas importantes questôes que decorrem do núcleo geográfico aquele que explora os possíveis territórios de atuação.

\footnotetext{
${ }^{4}$ Língua auxiliar que compreende um universo vocabular comum entre diferentes vernáculos.
} 
A pergunta que tangencia a raiz geográfica de todo ato transitivo (de onde e para onde se traduz/transcreve?) ganha, no interior do debate sobre a transcrição e suas vicissitudes, uma dimensão particular. Isso porque a própria noção de territorialidade musical é bastante difusa. O entendimento acerca dos espaços (físicos ou metafísicos) nos quais a música possivelmente se atualiza é bastante controverso e vem sendo alvo de um extenso debate nos estudos musicológicos ${ }^{5}$. Nas tradiçôes orais, que de forma mais radical dependem dos meandros da cultura e da memória social, uma infinidade de redes intertextuais percorre os produtos estéticos e é responsável por seus processos de significação, influindo não somente na reprodutibilidade, mas, antes, na própria organização material do produto. Nessas tradições, somos levados a crer que as territorialidades se confirmam nos e pelos rituais de performance.

Mas se a prática de performance se torna responsável pela territorialidade dos universos musicais de tradição oral, como poderíamos entender as localidades geográficas, de saída e chegada, no interior de uma atividade de transcrição que possui como objeto uma obra musical pensada e construída no silencioso recurso notacional? Para responder a essa pergunta, torna-se necessário trazer para o debate a discussão a respeito dos processos de fruição na arte.

Um setor da musicologia moderna tem se dedicado ao tema da origem da expressão musical. A pergunta pela possibilidade de a música, como expressão fundamentalmente acústica, existir no silêncio da partitura ou, de maneira oposta, apenas numa situação de performance, tornou-se o ponto nodal dessa problemática. De um lado da discussão, uma série de musicólogos - como Nicholas Cook, Robert Martin, entre outros - tem enxergado no performer a figura central na construção do processo de fruição e da memória musical. Segundo Cook,

Concebida, à maneira da crítica cultural, como um ato de resistência contra a autoridade e a completude do texto reificado, a performance se torna um veículo para a reabilitação dos interesses dos que são marginalizados pelo discurso musicológico tradicional: não apenas os performers, obviamente, mas também os ouvintes, pois, nas palavras de Robert MARTIN (1993, p.121, 123), "As performances, ao contrário das partituras, estão no coração do mundo do ouvinte... [enquanto que] as obras musicais, no mundo dos ouvintes, simplesmente não existem". Segue que "as obras musicais são ficções que nos permitem falar de uma maneira mais conveniente sobre as performances” (MARTIN, 1993, p.123), ou como coloca Christopher SMALL (1998, p.51), "uma performance não existe para que obras musicais sejam apresentadas, mas, pelo contrário, obras musicais existem para que o performer tenha algo para interpretar [perform]”. (COOK, 2006, p. 8)

\footnotetext{
${ }^{5}$ Uma série de pesquisas tem se ocupado da territorialidade musical, da espacialização e atualização de seu fenômeno. Dentre essas, podemos citar COOK (2006), MARTIN (1993), PIEDADE (2013).
} 
De fato, a música ocidental de concerto apresenta uma característica singular em relação aos demais universos da arte no que diz respeito ao processo fruitivo de sua "materialidade". Afinal, o acesso direto aos repertórios de sua vasta tradição escrita só é possível àqueles que dominam a leitura musical. Para os não-iniciados no código e para aqueles que não predispóem do conjunto de habilidades físicas necessárias à sua prática, o universo musical só é acessível de forma indireta, por meio de um desvio. Esse “atalho” oferecido aos não-musicistas corresponde a uma leitura já realizada da obra, a uma fruição já consumada do texto musical. A existência e necessidade de um mediador para esse processo - o intérprete, instrumentista ou cantor - atesta a especificidade da experiência com a arte sonora em relação às demais. O processo dialógico implícito na recepção de uma pintura ou escultura enquanto produto estético requer de seu contemplador só os sentidos que lhe são inatos. Já o dialogismo que percorre a fruição musical se vê mediado, em toda experiência dos nãoespecialistas no campo, pela figura do intérprete que promove, por meio de sua leitura e assinatura artística, as consequentes e potenciais catarses sensitivas. Em alguns casos, esse processo desborda a ponto de o intérprete e sua performance se substituírem aos papéis de compositor e obra, respectivamente.

\section{Fidelidade, ética e transcrição.}

Agora, cabe-nos pensar nas consequências dessa estruturação específica da música em relação a uma experiência como a transcrição, cujo principal campo de atuação é representado pela música de tradição escrita. Dentro da esfera da fidelidade - conceito tão ecoado na interpretação musical e em atividades como tradução e transcrição; presente também na musicologia moderna pelo movimento de "Interpretação Historicamente Informada" - parece-nos um equívoco determinar como ponto de partida, seja para qualquer operação transcricional ou mesmo interpretativa, a performance ou gravação de uma peça que foi previamente idealizada e registrada por meio da notação musical. A fidelidade, no caso da transcrição, deveria estar circunscrita à escrita da obra, assim como à rede de intertextualidades expressivas e culturais que subsistem nas "entranhas" de todo e qualquer texto, seja este verbal ou musical. A defesa do texto de origem como ponto de partida para o processo de transcrição/interpretação realizado no interior do universo musical de tradição escrita vai ao encontro 
de um ímpeto de eticidade para com o tecido expressivo-estético-idiomático em potência na escrita primeira da peça, que, nesse estágio, apresenta como única "tradução" a própria intenção e narrativa estético-composicional de seu criador. A melhor forma de confrontar, por via direta, a inventio de uma obra musical de tradição escrita e a razão de sua teia de relações expressivas, é por meio de sua própria escritura. Acessar a obra por outro suporte mediador - ou seja, já numa situação de performance ou por meio de gravações - configuraria um desvio dessa razão originária em potência no texto musical. Sendo assim, os procedimentos tradutórios e transcritivos que desenvolvem suas práticas por meio de derivações do texto de origem - gravação, performance ou tradução já realizada - apresentam concepções transitivas diversas da que defendemos aqui, cujo ponto irredutível repousa na intrínseca intimidade com o conceito de fidelidade e eticidade.

Para evitar equívocos, no entanto, é preciso desdobrar um pouco o argumento da fidelidade. O que acima se argumentou não pretende fazer eco à dualidade platônica - que revela sua polaridade entre os conceitos de original e simulacro -, que termina por levar a uma sacralização indevida do texto, como uma tese imperfectível de determinado conhecimento. Não há dúvidas de que no terreno da contemplação estética, diversamente da univocidade almejada e encontrada nas formulações das ciências exatas, a abertura a todo um universo infinito de leituras não apenas revela a profundidade do objeto da ação fruitiva, como também promove a incessante renovação do próprio artefato artístico. No entanto, é preciso considerar - principalmente para a discussão que se pretende exemplificar aqui - que a fonte da fruição, a razão que estabelece o devir dialógico do objeto artístico, se encontra em potência na própria materialidade da obra, no seu registro. Direcionando nossas análises para a prática da música ocidental de tradição escrita, podemos observar que por mais que essa expressão confirme sua especificidade na atividade do intérprete e no universo das performances que resultam de sua prática, ainda assim há de se concordar que a lei que estabelece a inteligibilidade de uma obra e o elo que instaura sua possibilidade residem no texto musical de origem. A questão levantada anteriormente sobre a raiz geográfica que conduz os pontos cardeais em uma atividade transcricional, encontra aqui seu repouso. $\mathrm{O}$ acesso às relações expressivo-mecânicas, as infinitas possibilidades de performance, a experiência e o processo de fruição, todos esses direcionamentos apresentam como fonte, dentro da concepção de transcrição musical defendida nesse trabalho, o texto primeiramente expresso por seu criador. $\mathrm{O}$ acesso mais íntimo à rede de influências que forma o 
universo estético do autor, o contato mais transparente com a malha cultural que sustenta e possibilita a origem da obra, todas essas experiências só se tornam possíveis por meio de um profundo exercício investigativo, no qual a peça de origem desempenha um papel basilar. A pragmática da experiência e o contágio advindo do próprio objeto artístico configuram apenas a etapa inicial desse fenômeno, que nada mais objetiva senão dar voz à própria dinâmica estética em potência na obra. Assim como acontece em toda atividade filosófica, após o estágio imanente da experiência, tem início uma série de reflexôes e análises que partem da conjuntura macroespacial da obra, atualizando-a no interior de um vasto universo cultural. Partindo dessa contingência de textualidades e reverberaçóes culturais, a reflexão se dirige a territórios microespaciais, pondo luz sobre os compostos estéticos e fazendo com que esses se tornem, enfim, reconhecíveis no interior de um complexo expressivo maior. Tal processo é fundamental para compreendermos o desenvolvimento do universo conotativo e a formação das redes significantes em imanência na obra. Sobre esse processo, referindo-se à poesia, diz Paul Ricoeur:

(...) nossas palavras têm, cada uma, mais de um sentido, como se vê nos dicionários. Chamamos isso de polissemia. O sentido é, a cada vez, delimitado pelo uso, o qual consiste essencialmente em triar a parte do sentido da palavra que convém ao resto da frase e como este concorre para a unidade do sentido exprimido e oferecido à troca. É a cada vez o contexto que, como se diz, decide sobre o sentido assumido pela palavra numa tal circunstância de discurso; a partir daí as disputas sobre as palavras podem ser sem-fim: o que você quis dizer? etc. É no jogo da questão e da reposta que as coisas se tornam mais precisas ou se embrulham. Pois não há apenas os contextos patentes, há também os contextos escondidos e o que chamamos conotaçôes, as quais nem sempre são intelectuais, mas afetivas, nem sempre são públicas, mas próprias a um meio, uma classe, um grupo, até mesmo um círculo secreto; há, assim, toda uma margem do não dito, percorrida por todas as figuras do escondido. (RICOEUR, 2012, p. 52)

Para realmente compreendermos esse complexo tecido de significâncias e conotações, não podemos escapar a uma profunda experiência de reflexão estabelecida com o objeto estético de origem, seja este musical, pictórico ou literário. Desta forma, concordamos que a prática transcricional deve manter, conforme expusemos até aqui, uma estreita relação com o texto da peça musical, no sentido de que sua atividade seja fundada e desenvolvida pela expressividade e pela organicidade em potência nesse mesmo texto, entendido como obra que nasce dos múltiplos traços subjacentes a uma cultura. 


\section{A relação entre "forma" e "fundo" como elemento central em uma operação transcritiva.}

A discussão conduzida até aqui em torno do núcleo geográfico, isto é, dos pontos de partida e chegada de uma atividade transcricional - trazendo para o debate conceitos como fidelidade, fruição e obra - nos leva por fim ao outro núcleo, aquele que se desenvolve em torno da raiz composicional da operação transcritiva. Como já exposto, se a fidelidade em uma transcrição musical converge para o texto de origem, para sua escritura inicial, quais as qualidades estruturais em potência na peça que seriam passíveis do compromisso ético e poético inerente a essa atividade? A resposta para essa pergunta igualmente advém de um exercício filosófico consubstanciado na experiência seguida da reflexão. A raiz composicional não apenas deve ser inteiramente esmiuçada pelo transcritor, como também deve configurar o núcleo que regula os procedimentos e as escolhas a serem tomadas na tarefa transcritiva. A relação entre idiomatismo instrumental e discurso expressivo-musical em potência no texto de origem, as poeticidades que permeiam a obra em seu específico período histórico, o reconhecimento dos traços composicionais: todos esses são elementos integrantes dessa unidade informativa que nos apresenta as espécies qualitativas em jogo numa transcrição. A fidelidade para com todas essas características experienciadas com a obra de origem, fruto de um compromisso ético e poético com a mesma, torna-se o principal escopo dessa atividade, orientando o transcritor na desconstrução das teias expressivo-idiomáticas em potência na peça a ser transcrita e na consequente tentativa de reconstrução das leis que regem essa interseção em imanência no texto fonte, revelada na dialética entre o discurso musical e o universo idiomático-instrumental. As teorias da tradução pósGoethe, cuja aproximação com a prática transcritiva acreditamos ser fundamental para retirar essa última de certo desapreço e desvalorização, têm uma mesma noção de proximidade com o texto de origem e com suas respectivas relações estabelecidas entre forma e fundo. É o que se encontra bem expresso por Mário Laranjeira:

Não se pode, pois, separar, na prática nem na teoria da tradução poética, a forma do fundo. Muito menos ver o conteúdo como elemento traduzível e a forma - esse adorno que poetizaria o fundo - como intraduzível. Toda a operação de tradução poética supóe uma visão dialética do texto que só reconhece as oposições na medida em que se integram numa unidade, numa totalização essencial. É um trabalho na cadeia dos significantes enquanto geradora de sentidos. É esse processo de geração de sentidos existente no texto de partida, a sua significância, que é trabalhado no ato tradutório de maneira a obter-se na línguacultura de chegada, não o mesmo fundo vestido de uma mesma forma, mas uma interação 
semelhante de significantes capaz de gerar semelhantemente a significância do texto. (LARANJEIRA, 2003, p. 29)

$\mathrm{Na}$ atividade de transcrição musical, forma e fundo também não devem ser separados e muito menos repelidos, como se a permanência de um dependesse do silenciamento do outro. Se, para simplificarmos a questão, entendermos a mecanicidade instrumental como forma e a expressividade musical como conteúdo, torna-se fundamental captá-las e compreendê-las em potência no texto como uma série de confluências híbridas, da mesma forma que Laranjeira as identifica no fenômeno tradutório, e isso a fim de alcançarmos o processo de formação da significância em música. Dito isso, é preciso que o transcritor esteja a par das estruturas responsáveis pela produção sonora do instrumento para o qual a obra foi escrita, para que, dessa forma, consiga apontar as relaçóes que esse universo idiomático original estabelece com o discurso musical em potência no texto de partida. Acreditando que essas relações tanto preenchem a condição transitiva de raiz composicional presente em qualquer processo de transcrição, quanto são uma resposta sintética para a pergunta realizada anteriormente - "O que se desloca em um processo transcricional?" -, a familiaridade com os princípios idiomáticos do instrumento para o qual a peça foi idealizada e escrita passa à condição de ferramenta indispensável numa atividade transcricional pautada pelo compromisso ético, poético e filosófico para com a obra de origem.

\section{Tempo de Bourée, BWV 1002: apontamentos analíticos e uma proposta de transcrição.}

Para um direcionamento prático ao debate aqui proposto, é necessário exemplificar os procedimentos envolvidos em uma atividade transcricional. Como ponto de partida, escolhemos o 4⿻ $^{\circ}$ movimento da Partita I para Violino Solo (BWV 1002), de J.S. Bach, cujo andamento na partitura aparece sob a indicação "Tempo de Bourrée”. Como ponto de chegada, optamos pela análise da transcrição para violão solo realizada por Andrés Segovia, sendo essa, talvez, a transcrição da BWV 1002 mais tocada nesse instrumento. As escolhas aqui tomadas decorrem da maior familiaridade dos autores com período, obra e instrumentos de origem e chegada. Contudo, os procedimentos, dinâmicas e análises em questão são potencialmente deslocáveis para outros universos repertoriais.

A Partita em Si menor BWV 1002 apresenta a forma de suíte instrumental solo (Allemande, 
Courante, Sarabande e Gigue), sendo que o último movimento, contudo, revela a substituição da Gigue pela Bourrée. Segundo LEDBETTER (2009, p. 108), "isso ocorre provavelmente pelo fato de a Double da sarabanda já ser em um compasso de 9/8, e não porque, como sugere Spitta, a Gigue dificilmente ser adequada para variaçôes”. Dentro do formato instrumental solo dessa suíte, Bach desenvolve o recurso composicional da variação, onde todos os movimentos apresentam suas diferenciações em doubles (Allemande/Double, Courante/Double, Sarabande/Double e Tempo de Bourée/Double). Nesse contexto, nota-se que Bach promove uma divisão de valores de tempo entre as danças e suas respectivas variações. Esse procedimento, tipicamente bachiano, era muito utilizado no desenvolvimento melódico de suas obras. As Doubles apresentam divisões de tempo que vão de semicolcheias na Alemande e na Courante, a tercinas na Sarabande e a um moto perpetuo em colcheias no Tempo di Bourrée. Neste último movimento, o discurso se desenvolve em compasso binário de 2/2, característico dessa espécie de dança. As bourrées são, de forma geral, danças de métrica simples e de caráter tendente à leveza e ao júbilo. Segundo Ledbetter:

\footnotetext{
A sensação de dois tempos no compasso, com o meio do compasso situado no contratempo, torna-se importante para a leveza da métrica desta dança. Tendo dito isso, o fortíssimo segundo tempo do compasso 1 , combinado com a leveza do segundo tempo do compasso 2, torna-se quase uma paródia da métrica da bourrée. O efeito é de jovialidade, não de sobriedade, no espírito do Kehraus alemão, ou como a última dança da noite. (LEDBETTER, 2009, p. 117-118)
}

A percepção do compasso binário se faz absolutamente necessária, tanto ao intérprete como ao transcritor, para que a dança apresente o ímpeto singelo e leve que lhe é característico.

FIGURA 1 - Compassos 1 a 11 do Tempo di Bourrée, BWV 1002. No trecho abaixo podemos visualizar a indicação de tempo $(2 / 2)$ e a dinâmica da métrica desse movimento.

\section{Tempo di Bourrée.}
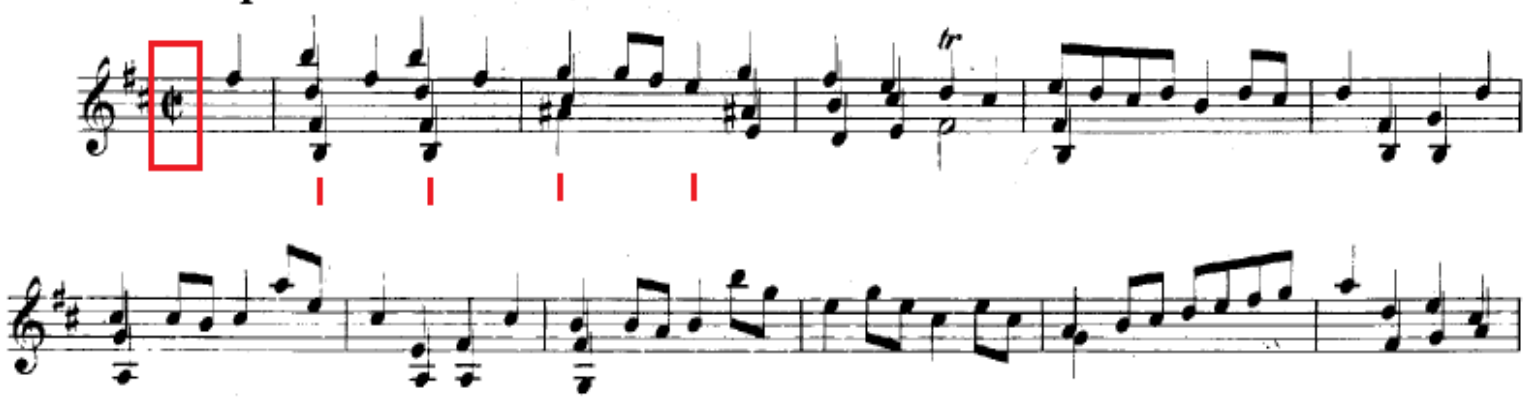

Fonte: DÖRFFEL (1879, p. 16) 
Contudo, além do compasso binário, há ainda mais uma característica que aponta para a atmosfera de leveza em potência na bourrée. Apesar da densa polifonia, presente em grande parte dessa peça, a técnica tradicionalmente usada pelos violinistas na articulação das estruturas verticais e contrapontos acaba apresentando um resultado sonoro que mais contribui para a volatilização dessa densidade do que para a afirmação de sua textura. $\mathrm{O}$ andamento marcado de dança força o violinista a atacar os acordes com arcadas mais rápidas e articuladas. Ao executar 3 ou 4 notas em um andamento mais acelerado, como é típico nas bourrées, as notas mais graves de cada acorde são tocadas muito rapidamente, soando muitas vezes como apojaturas da nota mais aguda, o que, de resto, é claramente perceptível em todas as gravaçôes desse movimento. Com isso, a textura polifônica da peça se torna, devido à própria condição mecânico-idiomática do instrumento em questão, mais rarefeita e leve.

Passemos agora para a análise do mesmo trecho na transcrição para violão solo de Andrés Segovia. Desnecessário dizer que Segovia foi um dos mais influentes violonistas do século XX, responsável por centenas de transcrições, muitas delas provenientes do repertório bachiano. Guiado bem menos por puros interesses musicológicos do que por prementes razóes de mercado, um de seus costumes era transcrever, de maneira isolada, movimentos e danças de suítes e sonatas originalmente escritas para violino ou violoncelo, combinando-os em programas de concertos e gravaçốes. $\mathrm{Na}$ transcrição da bourrée em tela, Segovia parece não achar relevante a manutenção da métrica típica dessa dança. O compasso composto de dois tempos, presente no texto de partida, é alterado no texto de chegada para um de quatro tempos simples (4/4). A nova sensação métrica, o adensamento textural provocado pelo acréscimo de vozes, além do prolongamento de algumas notas - procedimentos que observamos serem comuns nas transcrições de Segovia - acabam inviabilizando a percepção de uma atmosfera mais leve, fruto da interseção entre o idiomatismo violinístico e o discurso musical em potência no texto de origem. 
FIGURA 2 - Compassos 1 a 14 da transcrição para violão do Tempo di Bourrée, BWV 1002. No trecho, algumas das alterações feitas por Segovia: mudança de compasso, acréscimo de vozes e prolongamento de notas.

\section{BOURREE}

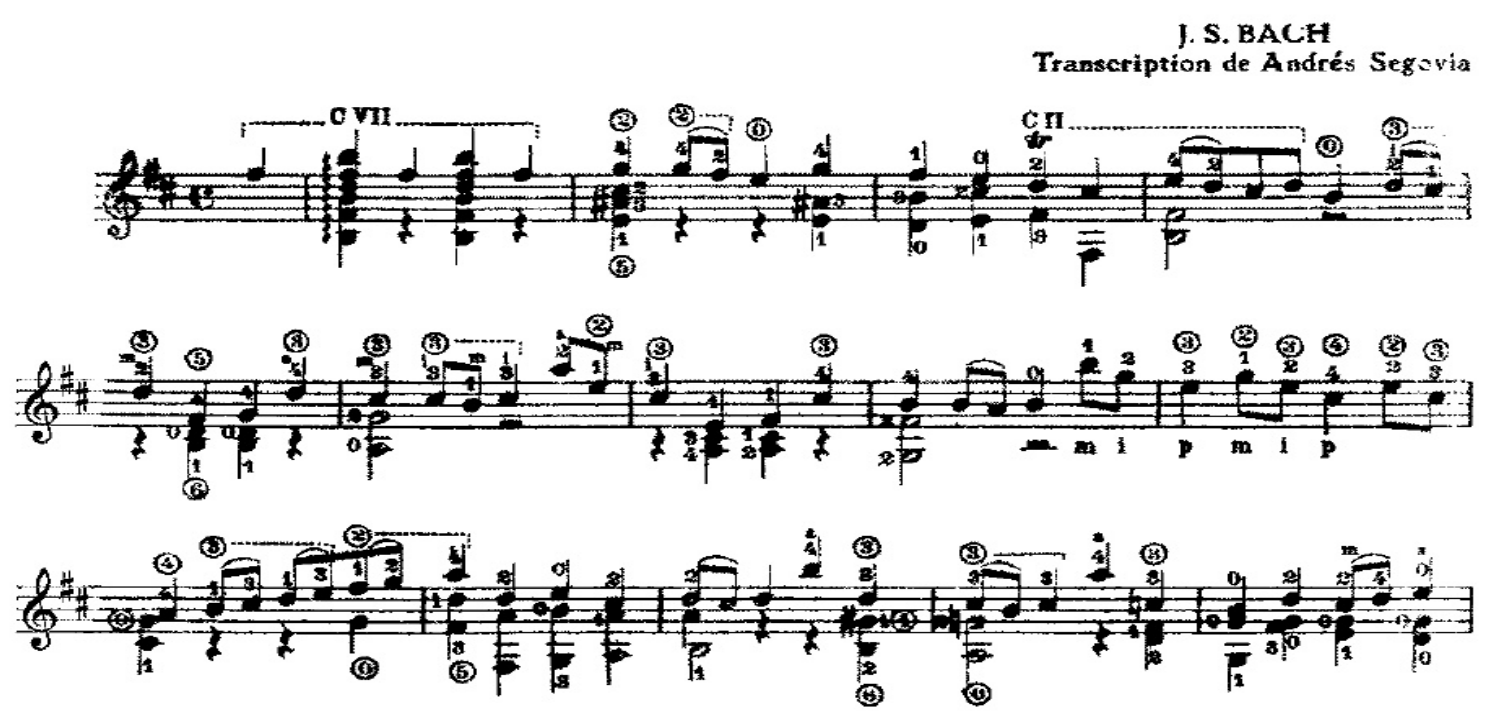

Fonte: SEGOVIA (1928, p. 2)

Conforme foi exposto anteriormente, apesar da densa textura polifônica da bourrée, em alguns momentos revelando um contraponto a 4 vozes, o funcionamento técnico-mecânico do violino compreende, na sua forma de recortar o discurso musical em potência na passagem em questão, de tal maneira a produção sonora dos acordes desse trecho que, em lugar de reforçar o efeito da polifonia, suaviza essa condição textural. Essa intrínseca condição mecânica do instrumento em questão, revelada no específico funcionamento dos golpes de arcada em acordes com mais de 2 notas, termina por ser um dos principais elementos do que chamamos de "raiz composicional" nesse trecho, resultando numa singular interseção mecânico-idiomática e em todo o decorrente universo afetivosensorial.

FIGURA 3 - Compassos 1 a 3 do Tempo di Bourrée, BWV 1002. As setas apontam o direcionamento da arcada e, consequentemente, da produção sonora dos acordes presentes no trecho.

\section{Tempo di Bourrée.}

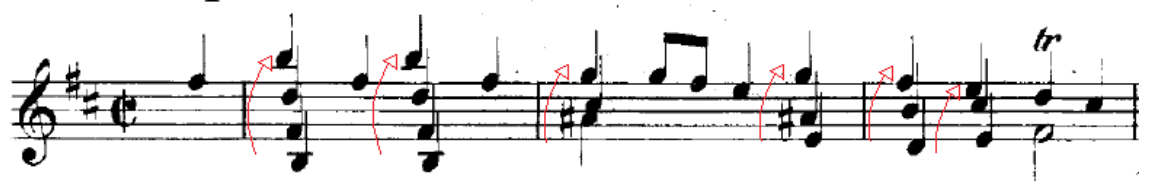

Fonte: DÖRFFEL (1879, p. 16) 
Na transcrição de Andrés Segovia, podemos observar uma indicação de arpejo nos acordes iniciais. O procedimento técnico do acorde arpejado implica, o mais das vezes, a realização com o polegar, cujo ataque é direcionado rumo à primeira corda do violão através do auxílio da movimentação do pulso e antebraço. Contudo, se levarmos em conta o universo idiomático do violão, percebemos que a ação física do acorde arpejado geralmente produz uma resultante sonora completamente oposta àquela obtida, no violino, pelo ataque do arco em acordes com mais de 2 notas. No violão, o acorde arpejado faz com que as notas golpeadas permaneçam soando, de maneira simultânea, enquanto dure a vibração das cordas. A técnica e o funcionamento mecânico do violino, por sua vez, não permitem o mesmo resultado que é absolutamente natural ao universo idiomático do violão. Contudo, é justamente o idiomatismo violinístico que privilegia e é responsável por um tipo de execução que enaltece o caráter marcado, dançante e leve deste movimento. O rápido ataque para as notas superiores e a impossibilidade de execução síncrona de todas as cordas do violino por meio do arco, o que faz com que as notas graves soem quase como apojaturas, resulta numa rarefação da textura polifônica e, consequentemente, numa passagem de sonoridade mais articulada e leve.

Sendo nosso objetivo a elaboração de uma transcrição que se revele fiel não somente às estruturas estético-significantes deste específico gênero de dança, mas também à interseção estabelecida entre a mecanicidade do violino e o discurso musical em potência no texto de origem, torna-se necessária a adoção de algumas medidas para que o universo idiomático de partida encontre no violão uma tradução que espelhe a sua tensão com o discurso. Uma delas seria, por exemplo, a reconfiguração da escrita de algumas notas no intuito de orientar os futuros intérpretes/violonistas em uma leitura, por assim dizer, mais "violinística" de seu instrumento. No exemplo abaixo apresentamos uma sugestão de transcrição para os primeiros compassos da bourrée: 
FIGURA 4 - Proposta de transcrição para violão solo do Tempo di Bourrée, BWV 1002. Compassos 1 a 8.

Tempo di Bourrée
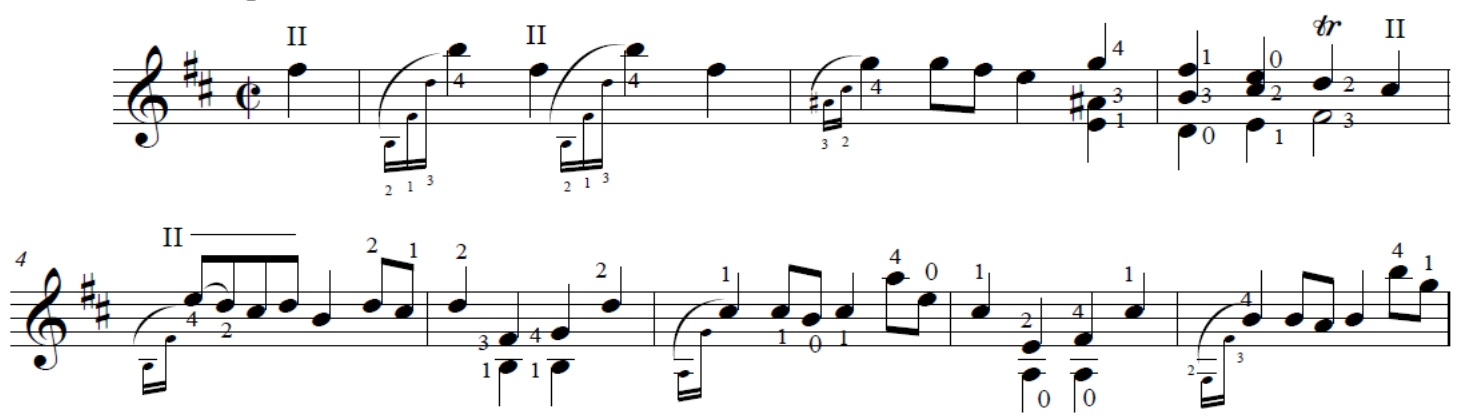

Fonte: Autores

De maneira bastante alternativa à transcrição de Segovia, mantivemos o compasso binário de 2/2, que não somente é uma característica básica desse tipo de dança, como é também absolutamente essencial para que a performance possa atingir a leveza inerente ao discurso musical da peça. Outro procedimento adotado nessa transcrição, e que pode gerar um certo estranhamento a princípio, está no tratamento dado às notas mais graves dos acordes de três e quatro vozes. Como relatado acima, a mecânica do violino não permite que cordas não adjacentes soem de forma síncrona por meio da ação do arco, o que acontece devido à geometria de disposição dessas no tampo do instrumento. Em acordes de 3 ou 4 notas (uma para cada corda), os violinistas se servem de um golpe de arco rápido e unidirecional, enfatizando as notas mais agudas. Ao contrário, as notas mais graves acabam soando como ligeiras apojaturas que se antecipam ao ataque da nota superior. No intuito de simular essa condição mecânica comum ao violino, direcionando a leitura dos violonistas para tal procedimento, foi reconfigurada a notação das alturas mais graves de alguns dos acordes de 3 e 4 notas, transformando-as de fato em apojaturas. Apesar do texto de origem não as apresentar dessa maneira, o funcionamento mecânico da técnica violinística assim as percebe, devido à densidade textural e também ao andamento esperado para esse tipo de dança. Apesar de o procedimento apresentar expressivo desvio notacional em relação à obra original, acreditamos - fiéis ao objetivo de tentar reconstruir, no texto de destino, a interseção estabelecida na origem entre idiomatismo e discurso 
musical $^{6}$ - que essa escolha se justifica ao permitir que as fronteias técnico-musicais do instrumento de chegada se alarguem, possibilitando ao violonista uma percepção incomum ao tradicional entendimento técnico do instrumento, porém, absolutamente condizente com as expressividades e significâncias em potência no texto de partida.

\section{Considerações finais.}

Nos limites desse artigo, procuramos discorrer sobre o fenômeno de transcrição musical e analisar alguns dos pressupostos teórico-práticos que tangenciam essa atividade transitiva. Se essa prática tem acompanhado a evolução e o desenvolvimento da música ocidental de tradição escrita, apresentando-se como tema recorrente em estudos e trabalhos que visam pôr em discussão seus processos e dinâmicas, acreditamos que o debate aqui proposto coloca luz em questóes ainda pouco visitadas, o que possibilita explorar seu funcionamento através de novas vias analíticas. Ao longo do tempo, constatamos que o pensamento acerca dessa prática têm contribuído, na grande maioria das vezes, para a formação de uma tradição transcricional que se vê refém do universo idiomático de destino, das condições mecânicas e do universo cultural orientados quase que exclusivamente à espacialidade de chegada (instrumento e intérprete, respectivamente), o que, de forma análoga, também aconteceu com a atividade tradutória. A subjetivação fruitiva, os discursos muitas vezes antagônicos acerca dessas atividades, o compromisso com um processo de reescrita o mais amistoso possível para o instrumento/língua/cultura de chegada, são questões que ainda ecoam nas atuais

\footnotetext{
${ }^{6}$ É importante insistir que o direcionamento dado à atividade transcricional no interior da reflexão aqui proposta vai diretamente ao encontro dos pensamentos de teóricos como Berman (2007), Benjamin (1979), Ricoeur (2012) e Torop (2000), nos quais o fenômeno tradutório - compreendido através de conceitos como obra, fidelidade e fruição - é analisado tendo em vista a interface construída na origem entre o funcionamento da língua e o universo abstrato das ideias. Cientes de que a analogia que aqui se constrói, e que pretendemos continuar desenvolvendo, muito se difere da própria atividade transcricional do próprio J.S. Bach, compositor utilizado nos exemplos, vale acrescentar uma nota de esclarecimento. $\mathrm{O}$ caminho analítico traçado neste artigo de forma alguma exclui outras maneiras de compreender a atividade transcricional, como as que eram utilizadas por Bach. Talvez a grande diferença entre essas concepções resida no entendimento do conceito de obra do qual se parte, uma vez que a tradição transcritiva sempre manteve uma estreita relação com os princípios práticos e performáticos do universo musical, que, como sabemos, pertencem mais à realidade extratextual, ao mundo do fruidor. Nossos esforços, de maneira oposta, são direcionados a compreender elementos anteriores à performance, à atualização do material musical. Acreditamos que a análise da arte sonora enquanto fenômeno linguístico e o processo de formação das significâncias em música compreendem algumas questôes que podem se beneficiar das aproximaçóes teóricas relativizadas nesse trabalho. Fundamentaçóes essas que mantém uma forte e profunda relação com a escrita da peça, com seus tecidos idiomático-discursivos, com suas diversas textualidades sócioestético-culturais, enfim, com muito daquilo que entendemos por obra.
} 
práticas de transcrição musical e tradução poética. Tratando especificamente do universo musical, o ímpeto performático inerente a essa arte acabou por catalisar o desenvolvimento da atividade transcricional, possibilitando não apenas uma expressiva expansão do repertório, inicialmente escasso no terreno da música instrumental, mas também todo um desdobramento da organologia e do mercado musical. Para corresponder a expectativas fruitivas, atualizadas nos ritos de performance, a atividade transcricional vem formatando suas dinâmicas de operacionalidade a fim de concretizar o desejo de apropriação (ou, talvez, colonização) do que é externo e estrangeiro à cultura do instrumento de destino. Entretanto, mais importante do que se reportar ao ímpeto performático da atividade musical, antes ainda de ter sua prática balizada pelo universo idiomático-cultural de chegada ou de circunscrever seu propósito na ampliação dos núcleos repertoriais, acreditamos e defendemos que a prática de transcrição musical possa cumprir um papel muito mais consciente e crítico, nivelando-se aos estudos que buscam investigar as diversas questóes da linguagem musical. Afinal, a transcrição possibilita evidenciar, da mesma forma que a tradução na literatura, sua atividade análoga, a razão do fenômeno de formação das expressividades e significâncias em música. A ação de descortinar o dialogismo estabelecido entre a mecanicidade instrumental e o universo expressivodiscursivo-estilístico em potência no texto de origem, é, para nós, a contribuição mais significativa do fenômeno transcricional, seu sentido mais profundo e verdadeiro.

Por meio dessa concepção ética, poética e filosófica do ato de se transcrever música, as aproximações mecânicas entre os universos sonoros que polarizam uma atividade transcricional não apenas se revelam factíveis como também possibilitam o desenvolvimento de analogias técnicas a partir dos estrangeirismos inerentes ao instrumento para o qual a obra foi originalmente pensada e escrita. Essa possibilidade de alargamento dos horizontes idiomáticos de chegada, um dos grandes trunfos dos fenômenos tradutórios e transcritivos, acaba criando novos caminhos para o desenvolvimento da técnica instrumental, além de conceder ao instrumentista maior compreensão dos limites territoriais da mecânica de seu instrumento. Essa possibilidade de sobreposição mecânica também aparece nas teorias de Berman, Benjamin e Ricoeur acerca da atividade tradutória. O acolhimento dos estrangeirismos, a sobreposição linguística fomentada por essas teorias, a proposta de perceber a língua para onde se traduz como estrangeira a si mesma, todos esses são procedimentos que formariam a verdadeira essência do ato de se traduzir. Analogamente, acreditamos que o processo 
transcricional opera, ou deveria operar, através dos mesmos princípios. São esses princípios e conceitos que permitem, no interior da concepção defendida nesse artigo, o alargamento dos universos idiomáticos/linguísticos, o contato mais íntimo com as expressividades e significâncias em potência nos textos musicais e verbais, a catalisação dos processos de desenvolvimento técnico/linguístico, enfim, o aprofundamento nos estudos que visam iluminar as relações entre música e linguagem.

\section{REFERÊNCIAS}

ASLANOV, Cyril. A tradução como manipulação. São Paulo: Perspectiva: Casa Guilherme de Almeida, 2015.

BACH, Johann Sebastian. Bourrée. Transcrição de A. Segovia. Mainz: Schott’s Söhne, 1928.

BACH, Johann Sebastian. Sonatas and Partitas, ed. Alfred Dörffel in the Bach-Gesellschaft, Volume 27. Leipzig: Breitkopf \& Hartel, 1879.

BARBEITAS, Flávio. Reflexôes sobre a prática da transcrição: as suas relaçóes com a interpretação na música e na poesia. Per Musi. Belo Horizonte, v.1, 2000. p. 89-97.

BENJAMIN, Walter. A tarefa do tradutor. Tradução de Fernando Camacho. Humboldt, Munique, F. Bruckmann, n. 40, p. 38-45, 1979.

BERMAN, Antoine. A tradução e a letra ou o albergue do longinquo. Tradução de Marie Helène Catherine Torres, Mauri Furlan e Andréia Guerini. Rio de Janeiro: 7Letras / PGET, 2007.

BOTA, João Victor. Aproximações entre tradutologia e os processos criativos em transcrições musicais do Rudepoema de Heitor Villa-Lobos. 2017. Tese (doutorado) - Universidade Estadual de Campinas, Instituto de Artes, Campinas, SP.

COOK, Nicholas. Entre o processo e o produto: música e/enquanto performance. Per Musi, Belo Horizonte, n.14, 2006, p.05-22.

COSTA, Gustavo Silveira. Seis Sonatas e Partias para violino solo de J.S. Bach ao violão: fundamentos para adaptação do ciclo. 2012. Tese (Doutorado em Musicologia) - Escola de Comunicação e Artes da Universidade de São Paulo, Universidade de São Paulo, São Paulo.

LARANJEIRA, Mário. Poética da Tradução. São Paulo: Editora da Universidade de São Paulo, 2003.

LEDBETTER, David. Unaccompanied Bach: Performing Solo Works. Yale University Press, 2009.

MARTIN, Robert L. Musical Works in the Worlds of Performers and Listeners. In: Michael Krausz (ed.), The Interpretation of Music: Philosophical Essays. Oxford: Clarendon Press: 119-27, 1993.

PEREIRA, Flávia. As Práticas de Reelaboração Musical. 2011. Tese (Doutorado em Musicologia) Escola de Comunicação e Artes, Universidade de São Paulo, São Paulo. 
PIEDADE, Acácio T. C. A teoria das tópicas e a musicalidade brasileira: reflexôes sobre a retoricidade na música. El Oido Pensante, v.1, p.1 - 23, 2013.

RIBEIRO, Sérgio Vitor de Souza. Reelaboraçôes para violão da obra de J.S. Bach: Análise das versóes de Francisco Tárrega e Pablo Marquez da Fuga BWV 1001. 2014. Dissertação (Mestrado em Música). Centro de Letras e Artes, Universidade Federal do Estado do Rio de Janeiro, Rio de Janeiro.

RICOEUR, Paul. Sobre a Tradução. Belo Horizonte: Editora UFMG, 2012.

RODRIGUES, Pedro João. Para uma Sistematização do Método Transcricional Guitarrístico. 2011. Tese (Doutorado em Música) - Departamento de Comunicação e Arte, Universidade de Aveiro, Aveiro.

SIMÃO, André Freitas. The process of arranging Silvius Leopold Weiss'solo lute works for guitar from the Robrau collection. Dissertação de mestrado, Universität Mozarteum Salzburg, 2013.

TOROP P. La traduzione totale. Ed. B. Osimo. Módena, Guaraldi Logos, 2000.

UNES, Wolney. Entre músicos e tradutores, a figura do intérprete. Editora da UFG - Universidade Federal de Goiânia, Coleção Quíron, 1998.

VALE, Victor Melo. A Tradutibilidade do Sentido: O processo de transcrição musical. Tese (Doutorado em Música) - Escola de Música, Universidade Federal de Minas Gerais, Belo Horizonte, 2018.

\section{SOBRE OS AUTORES}

Victor Melo Vale: Doutor em Música pela Universidade Federal de Minas Gerais, na linha de pesquisa da Performance Musical, com a tese "A Tradutibilidade do Sentido: o processo de transcrição musical", que recebeu o Prêmio UFMG de Teses em 2019. Foi também premiado em importantes concursos de violão, nacionais e internacionais, valendo citar o XIX Concurso de Violão Souza Lima (SP), o II Concurso de Violão da Faculdade Cantareira (SP), o I Concurso de Violão Maurício de Oliveira, entre outros. Atualmente é professor Adjunto II da Universidade Federal de Ouro Preto. ORCID: https://orcid.org/0000-0002-0105-695X. E-mail: victorhauser@gmail.com

Flavio Barbeitas: Bacharel e Mestre em Música pela UFRJ, Doutor em Estudos Literários pela UFMG. Professor Associado da Escola de Música da UFMG, atua nos níveis de Graduação e Pós-graduação. Além da atuação regular como violonista, dedica-se a aspectos teóricos da música em dois eixos principais: 1) a música na relação geral com a cultura brasileira e com os processos de construção e desconstrução da identidade nacional; 2) a música na relação com outras artes, principalmente a Literatura, a partir de temas como Música e Representação, Música e Linguagem. ORCID: https://orcid.org/0000-0002-6967-878X. E-mail: flaviobarbeitas@ufmg.br 